\title{
1 Impact of cobas PCR Media Freezing on SARS-CoV-2 Viral RNA Integrity and Whole
}

4 Patrick Benoit, ${ }^{\mathrm{a}}$ Floriane Point, ${ }^{\mathrm{b}}$ Simon Gagnon, ${ }^{\mathrm{c}}$ Daniel E. Kaufmann, ${ }^{\mathrm{b}, \mathrm{c}, \mathrm{d}}$ Cécile Tremblay, ${ }^{\mathrm{a}, \mathrm{b}, \mathrm{c}}$

5 Richard Paul Harrigan ${ }^{\mathrm{e}}$, Isabelle Hardy, ${ }^{\mathrm{a}, \mathrm{b}, \mathrm{c}}$ François Coutlée, ${ }^{\mathrm{a}, \mathrm{b}, \mathrm{c}}$ Simon Grandjean Lapierre, ${ }^{\mathrm{a}, \mathrm{b}, \mathrm{c}}$ \#

7 a Department of Microbiology, Infectious Diseases and Immunology, Université de Montréal,

8 Montréal, Québec, Canada

9 b Immunopathology Axis, Centre de Recherche du Centre Hospitalier de l'Université de Montréal,

10 Montréal, Québec, Canada

$11^{c}$ Microbiology and Molecular Biology Services, Centre Hospitalier de l'Université de Montréal,

12 Montréal, Québec, Canada

13 d Department of Medicine, Université de Montréal, Montréal, Québec, Canada

$14{ }^{\mathrm{e}}$ Department of Medicine, University of British Columbia, Vancouver, British Columbia, Canada

16 Running head: Impact of freezing for SARS-CoV-2 genome sequencing

18 \# Address correspondence to

19 Simon Grandjean Lapierre MD MSc ${ }^{\mathrm{a}, \mathrm{b}, \mathrm{c}} \#$

$20+1.514 .890 .8000$ Ext 20935

21 simon.grandjean.lapierre@umontreal.ca 


\section{For submission to Journal of Clinical Microbiology}

\section{ABSTRACT}

25 SARS-CoV-2 whole genome sequencing is an important molecular biology tool performed to

26 support many aspects of the response to the pandemic. Freezing of primary clinical nasopharyngeal

27 swab samples and shipment to reference laboratories is usually required since RNA sequencing is

28 rarely available in routine clinical microbiology laboratories where initial diagnosis and support

29 to outbreak investigations occur. The cobas PCR Media transport medium developed by Roche

30 facilitates high throughput analyses on cobas multianalyzer PCR platforms. There is no data on

31 the stability of SARS-CoV-2 RNA after freezing and thawing of clinical samples in this transport

32 medium, but potential denaturing of the molecular template could impair test results. Our objective

33 was to compare the quality and results of SARS-CoV-2 genomic sequencing when performed on

34 fresh or frozen samples in cobas PCR Media. Viral whole genome sequencing was performed

35 using Oxford Nanopore Technologies MinION platform. Genomic coverage and sequencing depth

36 did not significantly differ between fresh and frozen samples $(n=10)$. For samples with lower viral

37 inoculum and PCR cycle threshold above 30, sequencing quality scores and detection of single

38 nucleotide polymorphisms did not differ either. Freezing of cobas PCR Media does not negatively

39 affect the quality of SARS-CoV-2 RNA sequencing results and it is therefore a suitable transport

40 medium for outsourcing sequencing analyses to reference laboratories. Those results support

41 secondary use of diagnostic nasopharyngeal swab material for viral sequencing without

42 requirement for additional clinical samples. 
For submission to Journal of Clinical Microbiology

\section{INTRODUCTION}

44 SARS-CoV-2 viral genomic sequencing plays an important role in the short and long-term

45 responses to the COVID-19 pandemic including global and national surveillance of the virus

46 evolution, understanding of SARS-CoV-2 natural history of disease and outbreak investigations

47 (1-4). Viral whole genome sequencing primarily occurs in reference laboratories and is rarely

48 performed where clinical diagnosis or outbreak investigations happen. Therefore, freezing of

49 primary samples is required prior to viral genomic amplification and sequencing.

51 cobas PCR Media is a transport medium developed by Roche that simplifies linkage between pre-

52 analytical sampling and analytical testing and is adapted for high throughput analyses on cobas

53 multianalyzer PCR platforms. It contains guanidine hydrochloride which is a denaturing agent

54 used to dissociate nucleoproteins and inactivate RNases. The manufacturer does not recommend

55 freezing the cobas PCR Media because of risks of molecular template denaturation (5). Freezing

56 of other transport media was previously shown not to negatively impact the detection of SARS-

57 CoV-2 by RT-PCR (6). However, it is unknown whether, and how, freezing of cobas PCR Media

58 indeed denatures SARS-CoV-2 RNA and if it negatively affects viral genomic sequencing.

60 In this study, we compared the quality and results of SARS-CoV-2 whole genome sequencing

61 between fresh and frozen samples obtained from combined oral and nasopharyngeal swabs

62 (ONPS). We used matched split samples collected in cobas PCR Media and either processed

63 following collection and storage at $4^{\circ} \mathrm{C}$ or frozen for one week at $-80^{\circ} \mathrm{C}$ and thawed prior to

64 sequencing. Our protocol and analysis address the necessity for most clinical microbiology 
For submission to Journal of Clinical Microbiology

65 laboratories to refer frozen primary clinical samples that were used for diagnostic purposes to

66 reference laboratories in order to access viral genomic information.

68 MATERIALS AND METHODS

\section{CLINICAL SAMPLES}

70 Ten clinical samples were included in this study. All samples were a combined ONPS submitted

71 to our laboratory in cobas PCR Media initially found to be positive for SARS-CoV-2 using the

72 FDA emergency use authorization (EUA) approved and validated cobas 8800 automated RT-PCR

73 system which simultaneously tests both the ORF1 a/b and E-gene viral molecular targets (7). To

74 assess the impact of viral load or initial amount of RNA template on sequencing, we purposively

75 included samples testing positive at a broad range of cycle threshold $(\mathrm{Ct})$ from 14.4 to 34.7 for the

76 ORF1 a/b target. This strategy ensured inclusion of samples with low (high $\mathrm{Ct}$ ) and high (low Ct)

77 viral loads.

\section{FREEZING AND THAWING}

80 Following initial positive RT-PCR testing, samples were split in equal volumes. The first half of

81 each samples was maintained at $4^{\circ} \mathrm{C}$, according to manufacturer's recommendation, and then

82 processed for whole genome sequencing as described below. The second half of each sample was

83 frozen at $-80^{\circ} \mathrm{C}$ for 7 days and thawed. RT-PCR was then repeated using the same cobas 8800

84 system and viral genomic sequencing was performed using identical methods. 


\section{For submission to Journal of Clinical Microbiology}

87 Viral RNA was extracted from $0.2 \mathrm{~mL}$ of cobas PCR Media using Maxwell® 16 instrument

88 (Promega, Madison, WI, USA) for final elution in $30 \mu \mathrm{L}$. Viral whole genome sequencing was

89 performed using the ARTIC Network V3 protocol on Oxford Nanopore Technologies (ONT)

90 (Oxford, United Kingdom) MinION® long read sequencing platform. Since its initial publication

91 online in January 2020, the ARTIC protocol has become one of the most widely used approach to

92 SARS-CoV-2 genomic sequencing. This protocol has yielded a significant sequence contribution

93 to the GISAID global database and is currently used for surveillance by many public health

94 agencies $(8,9)$. Briefly, genome amplification was performed by reverse transcriptase multiplex

95 PCR using nCoV-2019 V3 primer combinations (Integrated DNA Technologies). This set of

96 primers was previously shown to produce high genomic coverage with low variance on the whole

97 viral genome (8). RT-PCR amplicons were assessed by Qubit ${ }^{\circledR}$ fluorometric DNA Quantification

98 (Thermo Fisher Scientific, Waltham, MA, USA). For samples with post RT-PCR DNA quantity

99 below $250 \mathrm{ng}$, we omitted the dilution step of the sample in $45 \mu \mathrm{L}$ of molecular grade water before

100 library preparation as recommended in the ARTIC protocol. Such low inoculums were observed

101 in three samples with both ORF1 a/b and E-gene targets Cts over 30 (samples 1, 2, 3). Sequencing

102 libraries were prepared following ONT protocol for genomic DNA with native barcoding and

103 using 9.4.1 flow cells on the MinION® platform. Raw sequencing reads fast5 files were base called

104 with high accuracy using ONT proprietary software Guppy (v3.4.5). Reads were demultiplexed

105 and filtered using the online available ARTIC network bioinformatic pipeline solution (10). This

106 filtering process includes exclusion of sequencing reads respectively below 400 and above 700

107 base pairs which do not correspond to expected amplicons length resulting from the RT-PCR

108 primer set. Reads were mapped to the Wuhan-Hu-1 SARS-CoV-2 reference genome (GeneBank

109 accession number MN908947.3) using minimap2 (v2.17). Predominantly sequenced nucleotides 


\section{For submission to Journal of Clinical Microbiology}

110 at positions for which a minimal depth of 20 reads had been achieved were used to generate

111 consensus viral genomic sequences. Potential subpopulations or mixed infections were not

112 considered, and hence a unique consensus sequence was generated for each isolate.

\section{DATA ANALYSIS}

115 We compared mean sequencing Q-scores with corresponding error rates and accuracy, single 116 nucleotide polymorphisms (SNPs) identification and diversity of sequenced alleles on identified

117 SNP genomic positions. We used those later metrics as surrogate markers of post-freezing viral

118 RNA integrity. Q-scores represent ONT's sequencing platform and base calling software internal

119 assessment of sequencing read quality. The Q-score of a given base is defined as Q $=10 \log _{10}(\mathrm{e})$

120 where (e) is the estimated probability of the base call being wrong. We used a two-tailed paired

121 samples t-test with an alpha value of 0.05 to compare pre- and post-freezing variables. All

122 statistical analyses were performed using GraphPad Prism (San Diego, CA USA).

124 To simulate prospective outbreak investigation, we supplemented the pre- and post-freezing

125 sequence datasets with a back catalog of 50 SARS-CoV-2 genomic sequences from our institution

126 (unpublished data) hence generating two mocked nosocomial viral pangenomes. We

127 independently analyzed both augmented data sets as if searching for potential transmission

128 clusters. Consensus sequences were compared, and phylogenetic trees were built using UGENE

129 (v37) with the PHYLIP Neighbor Joining method without bootstrapping. To simulate national

130 surveillance and assessment of circulating viral clades, we independently compared the pre- and

131 post-freezing sequence datasets with published and well described SARS-CoV-2 reference

132 genomes submitted to Nextstrain (https://nextstrain.org/sars-cov-2/) (11). 
For submission to Journal of Clinical Microbiology

134 All laboratory testing including sequencing and data analyses were performed in Centre

135 Hospitalier de l'Université de Montréal. Patients' symptoms nature and relative temporality with

136 clinical sampling, or potential person to person transmission events were not taken into

137 consideration.

\section{DATA AVAILABILITY}

140 SARS-CoV-2 sequences from this study are available at GenBank under continuous accession 141 numbers MW309425 to MW309442.

\section{RESULTS}

\section{RT-PCR}

145 Upon initial testing after maintenance of clinical samples at $4^{\circ} \mathrm{C}$ in cobas PCR Media, RT-PCR

146 Cts ranged from 14.4 to 34.7 and 14.9 to 34.9 respectively for the ORF1 a/b and E-gene targets.

147 After freezing for 7 days at $-80^{\circ} \mathrm{C}$, RT-PCR Cts ranged between 17.8 to 31.8 and 17.9 to 33.8 for

148 the same targets. No statistically significant difference was observed between pre- and post-

149 freezing Cts for the ORF1 a/b target ( $p$-value 0.64$)$. One sample only became positive on the E-

150 gene target after freezing. Excluding this sample from the analysis, post-freezing Cts for the E-

151 gene target were 1.1 Ct higher after freezing ( $p$-value 0.01) (Table 1).

\section{VIRAL GENOMIC SEQUENCING}

154 No statistically significant difference was observed between the sequencing yields before or after

155 freezing. Indeed, freezing did not negatively impact the total number of sequenced bases and 


\section{For submission to Journal of Clinical Microbiology}

156 mapped reads with pre- / post-freezing mean deltas of $11 \mathrm{Mb}(p$-value 0.57$)$ and 938 reads $(p$ -

157 value 0.31 ) for those key metrics. Also importantly, 20X sequencing depth, allowing for wild type

158 or variant allelic identification within our protocol, was achieved for an average of $83.9 \%$ and

$15983.7 \%$ of the viral genome respectively before and after freezing ( $p$-value 0.90) (Table 2). Such

160 similarity was also observed for all other evaluated depth thresholds (1X, 5X, 10X, 50X). As

161 expected, sequencing data yield, depth and coverage were inversely correlated to the Ct value both

162 in pre- (p-value 0.0007$)$ and post-freezing (p-value 0.0003$)$ samples. Less sequencing data was

163 hence generated in the sub-group of low viral inoculum and high Ct samples 1,2 and 3 but freezing

164 did not negatively impact sequencing yields in this subgroup either (Fig. 1).

166 No statistically significant decrease was observed in Q-scores ( $p$-value 0.07) and base call

167 accuracy ( $p$-value 0.10) after freezing (Table 3). Except for samples 1 (ORF1 a/b Ct 34.74) and 2

168 (ORF1 a/b Ct 32.16), freezing did not impact SNP detection and identified mutations were

169 identical in both sequencing analyses. Looking in more depth at each single read for those specific

170 mutation sites, the percentage of alternate bases leading to SNP calling did not significantly change

171 after freezing ( $p$-value 0.31). This ratio of variant versus wild type alleles at each mutation site

172 was the same before and after freezing and suggests that the viral molecular template was not

173 significantly degraded by the freezing process in cobas PCR Media.

175 In the mocked outbreak investigation, samples with higher genomic similarity were identified.

176 Although our study was not a molecular epidemiology study and did not include clinical

177 correlation with putative transmission events, those molecular clusters were identical in both pre-

178 and post-freezing analyses (Fig. 2). For the surveillance clade typing simulated application, 


\section{For submission to Journal of Clinical Microbiology}

179 phylogenetic placement was also identical in the pre- and post-freezing mocked data sets (Fig. 3).

180 For viral clade typing and comparison to reference genomes, samples 1 and 2 could not be included

181 in the analysis because of too small genomic coverage. All phylogenetic placement results were

182 expected and in agreement with previously described findings on identical SNP typing.

\section{DISCUSSION}

185 In our study, a single freeze - thaw cycle of ONPS clinical samples in cobas PCR Media did not 186 significantly impact analytical sensitivity of SARS-CoV-2 RT-PCR on cobas $8800 \AA$ automated 187 system on this limited set of samples. Although we observed a Ct increase of 1.1 ( $p$-value 0.01$)$ 188 after freezing for the E-gene target, one of our samples was also found to be positive for this target 189 only after freezing. Freezing the sample in cobas PCR Media did not degrade viral molecular

190 templates and did not negatively affect viral genomic sequencing analyses. Khiri et al had

191 previously shown that freezing of cervical samples in cobas PCR Media did not negatively impact

192 the sensitivity of PCR for human papillomavirus detection (12). Our study confirms this holds true

193 for SARS-CoV-2. To our knowledge, this is the first study to formally evaluate the impact of

194 freezing clinical samples in cobas PCR Media for downstream sequencing analyses either for

195 SARS-CoV-2 or for any other target pathogen or molecular template. Our study confirms the

196 ability of cobas PCR Media to maintain SARS-CoV-2 genomic RNA at $-80^{\circ} \mathrm{C}$ for subsequent

197 sequencing analyses. Note that the PCR amplicons generated in this study are relatively small

198 ( $\sim 400 \mathrm{bp}$ ), so this protocol may be more robust to RNA damage than methods which require long,

199 intact starting molecules. Our results should also not be generalized to other transport media 200 without independent confirmation. 


\section{For submission to Journal of Clinical Microbiology}

202 Our study included three samples with RT-PCR Cts above 30.0 which are considered to have a

203 lower viral load. For those samples, SNP calling showed variability and genomic coverage was

204 insufficient to allow detailed phylogenetic analyses. This phenomenon was observed both before

205 and after freezing and is hence believed to be due to low viral inoculum rather than transport

206 medium related viral RNA denaturation. Our study included only 10 samples but the extensive

207 comparability between pre- and post-freezing sequencing results suggests that a higher

208 denominator would not have led to different conclusions. It is possible that a freezing period longer

209 than 7 days would have led to worse sequencing results after thawing but our protocol did not

210 assess such longer-term effect. Seven days represents a sufficient delay for transportation to

211 reference laboratories performing viral sequencing and our study hence provides meaningful

212 information to clinical laboratories involved in routine diagnostic testing.

\section{CONCLUSION}

215 Our study demonstrates that the freezing of cobas PCR Media at $-80^{\circ} \mathrm{C}$ does not affect viral

216 genomic sequencing quality and results for SARS-CoV-2. The consistent results between pre- and

217 post-freezing support potential secondary use of diagnostic oral and nasopharyngeal swab material

218 for viral sequencing without requirement for additional clinical sampling. Our findings will

219 simplify the collection and storage of samples in laboratories where this transport medium is 220 utilized. 
bioRxiv preprint doi: https://doi.org/10.1101/2021.02.05.430022; this version posted February 8, 2021. The copyright holder for this preprint

(which was not certified by peer review) is the author/funder, who has granted bioRxiv a license to display the preprint in perpetuity. It is made available under aCC-BY-NC-ND 4.0 International license.

For submission to Journal of Clinical Microbiology

\section{ACKNOWLEDGEMENT}

222 This study was funded by the Réseau SIDA-Maladies Infectieuses of the Fond de Recherche Santé

223 Québec, Roche Diagnostics (Laval, Canada) and CIHR/CITF grant VR2-173203. The funders had

224 no role in study design, data collection and interpretation, or the decision to submit the work for 225 publication. 
For submission to Journal of Clinical Microbiology

\section{REFERENCES}

227 - 1. Lo SW, Jamrozy D. 2020. Genomics and epidemiological surveillance. Nat Rev $228 \quad$ Microbiol 18:478.

229 - 2. Choi B, Choudhary MC, Regan J, Sparks JA, Padera RF, Qiu X, Solomon IH, 230 Kuo HH, Boucau J, Bowman K, Adhikari UD, Winkler ML, Mueller AA, Hsu TY, 231 Desjardins M, Baden LR, Chan BT, Walker BD, Lichterfeld M, Brigl M, Kwon DS, Kanjilal S, Richardson ET, Jonsson AH, Alter G, Barczak AK, Hanage WP, Yu XG, Gaiha GD, Seaman MS, Cernadas M, Li JZ. 2020. Persistence and Evolution of SARSCoV-2 in an Immunocompromised Host. N Engl J Med doi:10.1056/NEJMc2031364.

235 - 3. Meredith LW, Hamilton WL, Warne B, Houldcroft CJ, Hosmillo M, Jahun AS, 236 Curran MD, Parmar S, Caller LG, Caddy SL, Khokhar FA, Yakovleva A, Hall G, 237 Feltwell T, Forrest S, Sridhar S, Weekes MP, Baker S, Brown N, Moore E, Popay A, 238 Roddick I, Reacher M, Gouliouris T, Peacock SJ, Dougan G, Torok ME, Goodfellow I. 2020. Rapid implementation of SARS-CoV-2 sequencing to investigate cases of healthcare associated COVID-19: a prospective genomic surveillance study. Lancet Infect Dis

242 - 4. Wise J. 2020. Covid-19: New coronavirus variant is identified in UK. BMJ $243 \quad 371: m 4857$.

$244 \quad$ - 5. Roche. 2019. Qualitative nucleic acid test for use on the cobas 6800/8800 $245 \quad$ Systems.

246 - 6. Rogers AA, Baumann RE, Borillo GA, Kagan RM, Batterman HJ, Galdzicka MM, Marlowe EM. 2020. Evaluation of Transport Media and Specimen Transport 
For submission to Journal of Clinical Microbiology

Conditions for the Detection of SARS-CoV-2 by Use of Real-Time Reverse

Transcription-PCR. J Clin Microbiol 58.

- 7. Boutin CA, Grandjean-Lapierre S, Gagnon S, Labbe AC, Charest H, Roger M,

Coutlee F. 2020. Comparison of SARS-CoV-2 detection from combined nasopharyngeal/oropharyngeal swab samples by a laboratory-developed real-time RTPCR test and the Roche SARS-CoV-2 assay on a cobas 8800 instrument. J Clin Virol 132:104615.

- 8. Tyson JR, James P, Stoddart D, Sparks N, Wickenhagen A, Hall G, Choi JH, Lapointe H, Kamelian K, Smith AD, Prystajecky N, Goodfellow I, Wilson SJ, Harrigan R, Snutch TP, Loman NJ, Quick J. 2020. Improvements to the ARTIC multiplex PCR method for SARS-CoV-2 genome sequencing using nanopore. bioRxiv doi: $10.1101 / 2020.09 .04 .283077$. Accessed December 22, 2020.

- 10. Nick Loman WR, Andrew Rambaut. 2020. ARTIC-nCoV-bioinformaticsSOPv1.1.0. https://artic.network/ncov-2019/ncov2019-bioinformatics-sop.html. Accessed 612-2020. Bedford T, Neher RA. 2018. Nextstrain: real-time tracking of pathogen evolution. Bioinformatics 34:4121-4123.

268 - 12. Khiri H, Camus C, Portugal M, Penaranda G, Boyer S, Halfon P. 2014. [Cytological and virological medium performance and stability assessment using the 
bioRxiv preprint doi: https://doi.org/10.1101/2021.02.05.430022; this version posted February 8, 2021. The copyright holder for this preprint (which was not certified by peer review) is the author/funder, who has granted bioRxiv a license to display the preprint in perpetuity. It is made available under aCC-BY-NC-ND 4.0 International license.

For submission to Journal of Clinical Microbiology

cobas 4800 HPV test (Roche Diagnostics) used in France]. Ann Biol Clin (Paris) 72:213-

271

23.

272 


\section{FIGURES}

274 Figure 1 - ORF1 a/b Ct value correlation with 20X genomic sequencing coverage

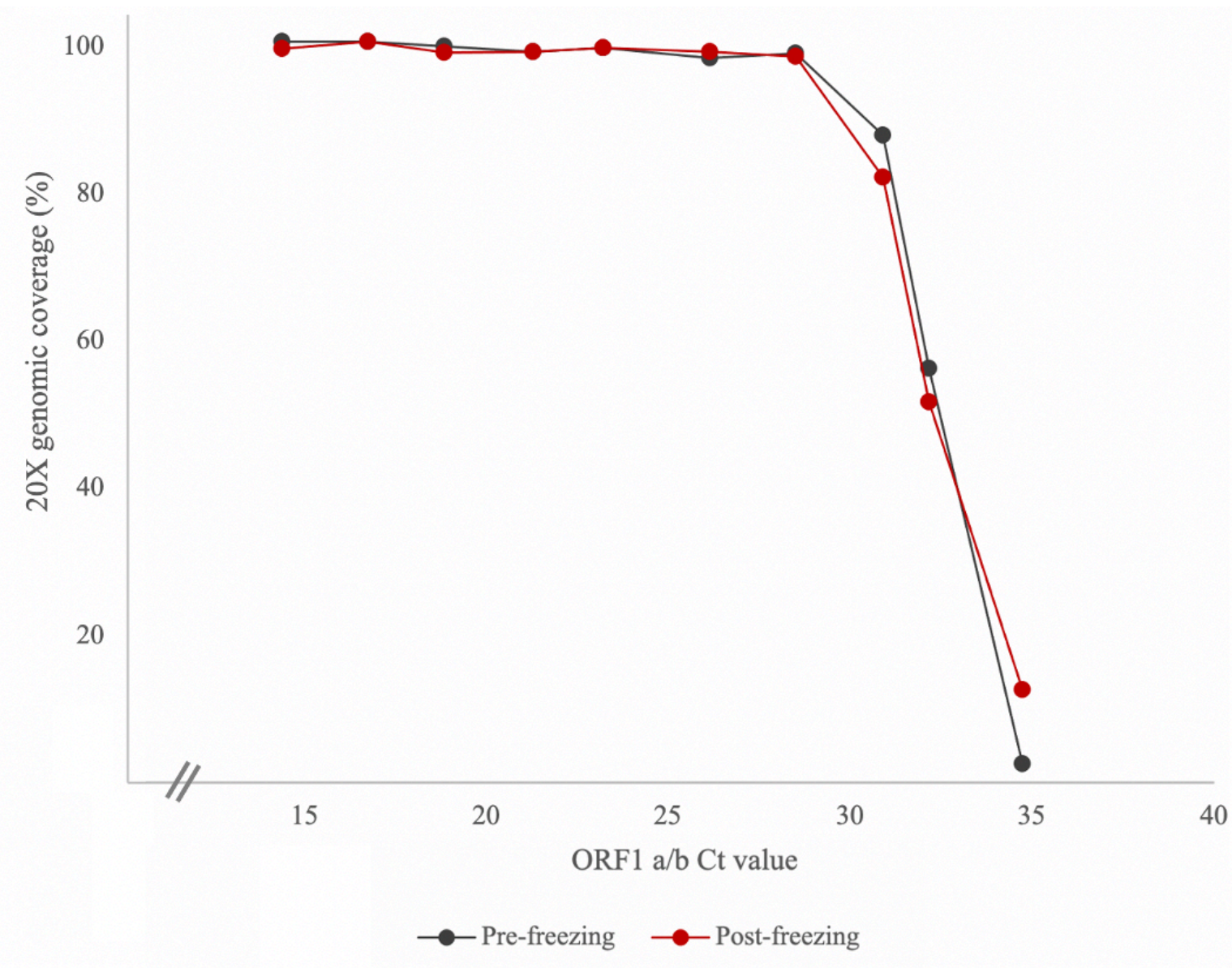

275

276 Figure 1 - Coverage of genome at $20 \mathrm{X}$ in relation to pre-freezing $\mathrm{Ct}$ value for ORF1 a/b. Less sequencing data was generated with

277 samples with higher cycle thresholds $(\mathrm{Ct})$ but freezing did not negatively impact sequencing yields. 


\section{Figure 2 - Simulated SARS-CoV-2 outbreak investigation}

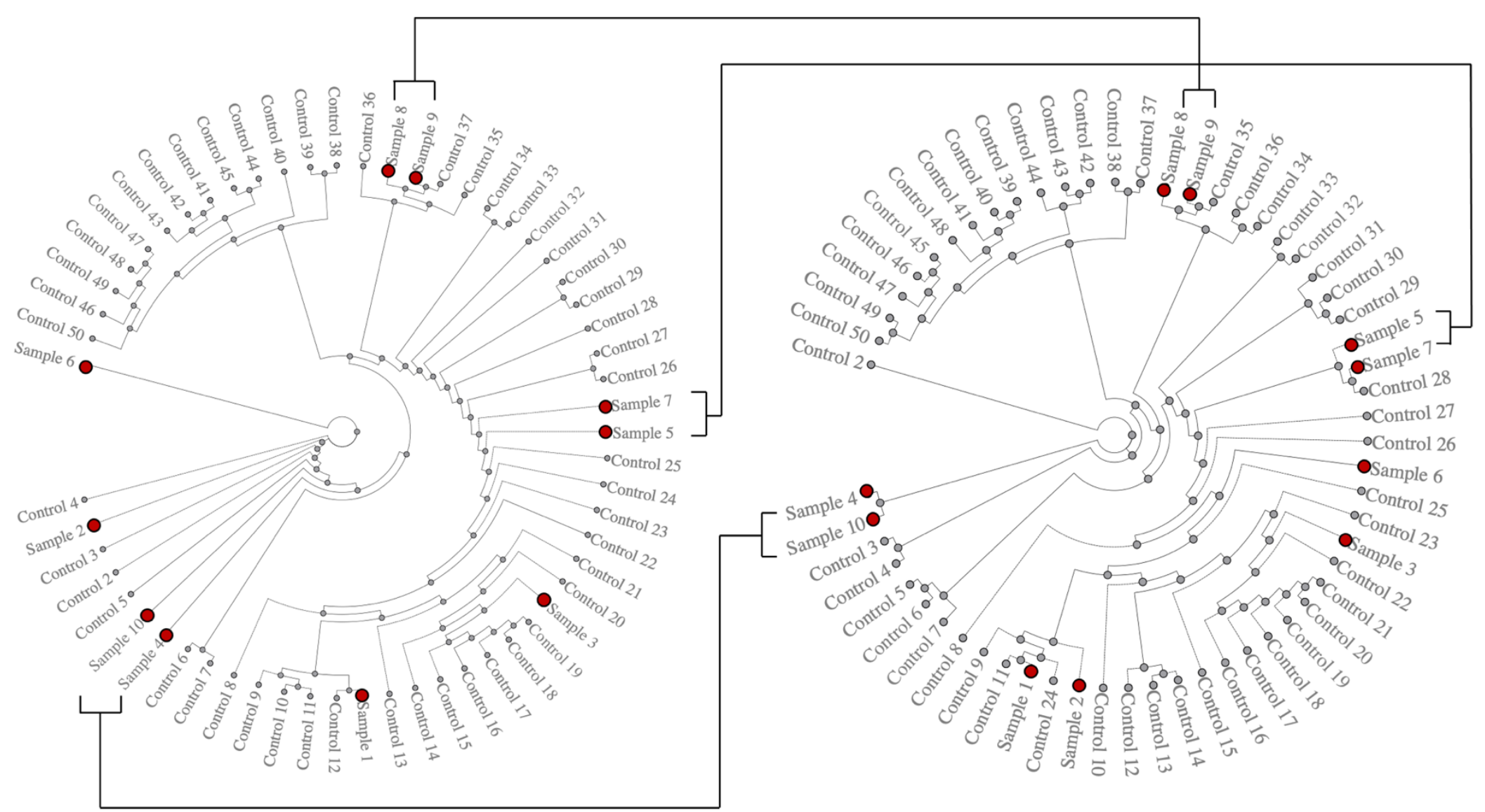

280 Figure 2 - A simulated outbreak investigations with a back catalog of 50 SARS-CoV-2 genomic sequences from our institution

281 (unpublished data). Phylogenetic trees were constructed using UGENE (v37) with the PHYLIP Neighbor Joining method without

282 bootstrapping. Pre- (left) and post-freezing (right) genomic sequences show identical potential outbreak clusters within our samples. 


\section{Figure 3 - SARS-CoV-2 Study Isolates Placement Within Global Reference Sequences}

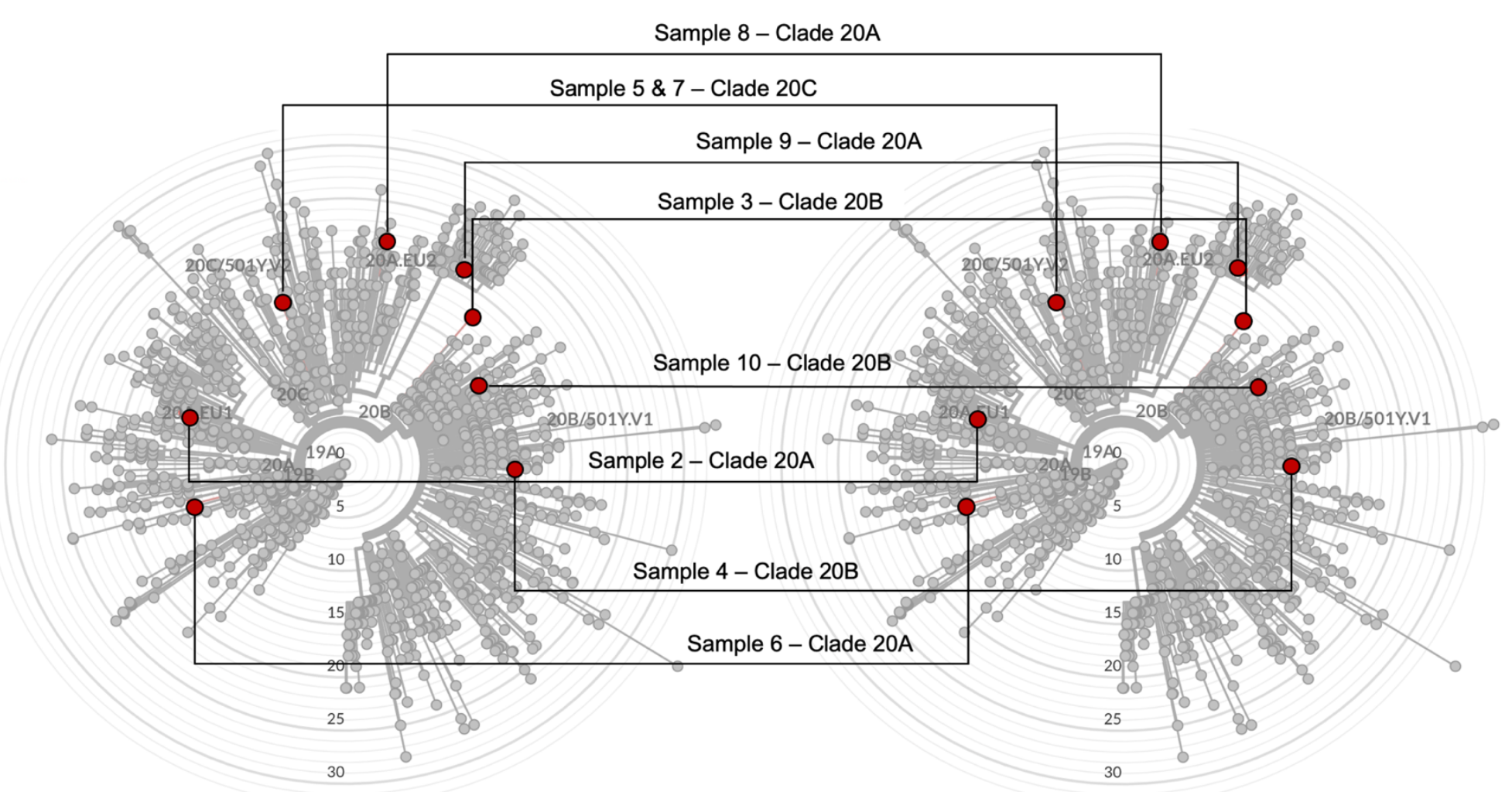

285 Figure 3 - Radial rooted phylogenetic representation of SARS-CoV-2 reference sequence submitted to Nextstrain 286 (https://nextstrain.org/sars-cov-2/). Pre- (left) and post-freezing (right) genomic sequences (red) showing identical phylogenetic 287 placement within global reference sequences (grey). 
For submission to Journal of Clinical Microbiology

\section{TABLES}

290 Table 1 : Impact of cobas PCR Media freezing on SARS-CoV-2 RT-PCR Ct levels

\begin{tabular}{|c|c|c|c|c|c|c|}
\hline & \multicolumn{2}{|l|}{ PRE } & \multicolumn{2}{|l|}{ POST } & \multicolumn{2}{|c|}{ DELTA (PRE - POST) } \\
\hline & ORF1 a/b & E-gene & ORF1 a/b & E-gene & ORF $1 \mathrm{a} / \mathrm{b}$ & E-gene \\
\hline & $\mathrm{CT}$ & $\mathrm{CT}$ & $\mathrm{CT}$ & $\mathrm{CT}$ & $\Delta \mathrm{CT}$ & $\Delta \mathrm{CT}$ \\
\hline 1 & 34.7 & NEG & 31.8 & 33.8 & 3.0 & $\mathrm{~N} / \mathrm{A}$ \\
\hline 2 & 32.2 & 34.9 & 30.4 & 34.5 & 1.8 & 0.4 \\
\hline 3 & 30.9 & 32.4 & 30.8 & 33.2 & 0.1 & -0.8 \\
\hline 4 & 28.5 & 29.4 & 28.3 & 29.4 & 0.2 & -0.1 \\
\hline 5 & 26.1 & 26.5 & 26.4 & 27.4 & -0.3 & -0.9 \\
\hline 6 & 23.2 & 23.3 & 24.0 & 24.5 & -0.8 & -1.2 \\
\hline 7 & 21.3 & 21.6 & 23.0 & 23.2 & -1.7 & -1.6 \\
\hline 8 & 18.9 & 19.2 & 20.4 & 20.9 & -1.6 & -1.8 \\
\hline 9 & 16.7 & 16.6 & 16.9 & 17.4 & -0.1 & -0.8 \\
\hline 10 & 14.4 & 14.9 & 17.8 & 17.9 & -3.4 & -3.0 \\
\hline Mean & 24.7 & 24.3 & 25.0 & 26.2 & -0.3 & -1.1 \\
\hline p-value & & & & & 0.64 & 0.01 \\
\hline
\end{tabular}

291

292 Table 1 - Difference in SARS-CoV-2 RT-PCR Ct levels after 7-day freezing in cobas PCR Media. Samples are presented in

293 decreasing order of Ct value on pre-freezing ORF1 a/b RT-PCR. 
For submission to Journal of Clinical Microbiology

294 Table 2 - Impact of freezing on SARS-CoV-2 Genomic Sequencing Data Yield

295

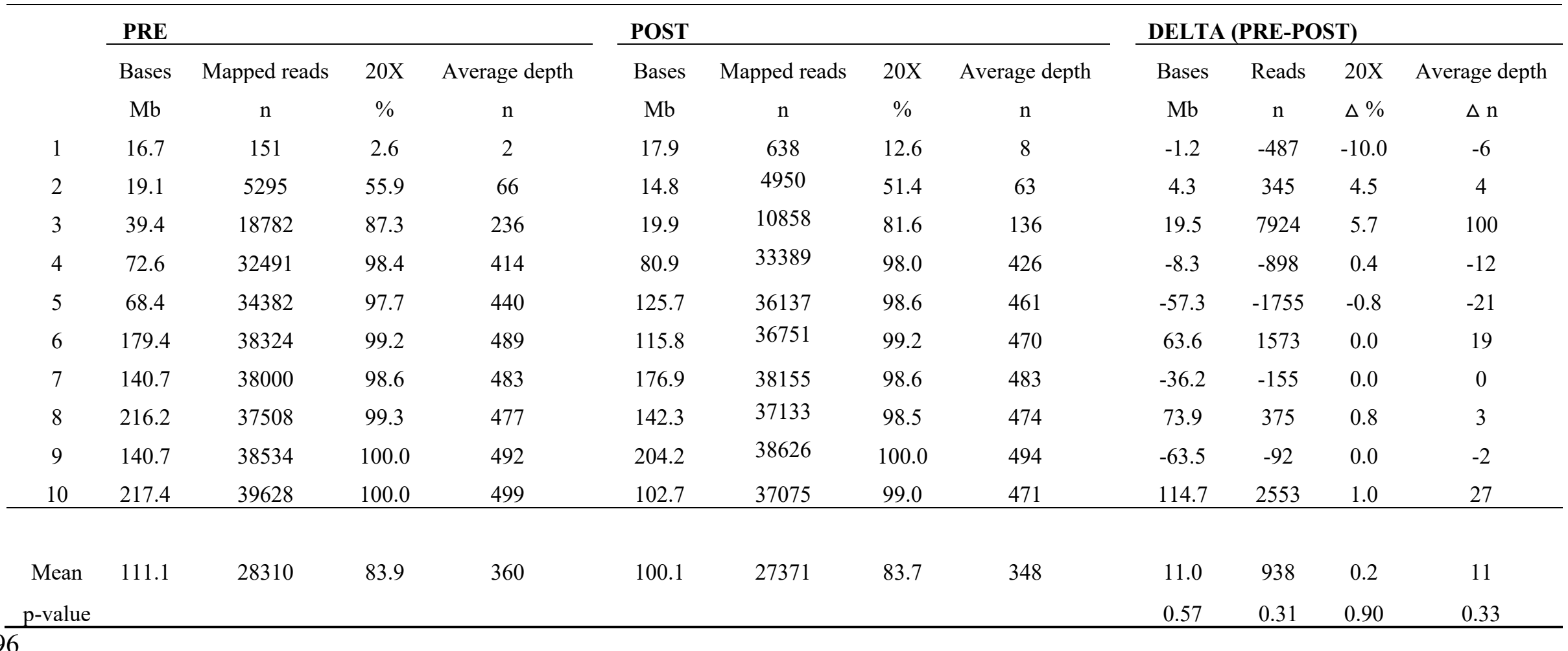

297 Table 2 - Difference in SARS-CoV-2 sequencing generated bases, reads and corresponding genomic coverage at various depth

298 thresholds after 7-day freezing in cobas PCR Media. Samples are presented in decreasing order of Ct value on pre-freezing ORF1 a/b

299 RT-PCR. 
For submission to Journal of Clinical Microbiology

300 Table 3 - Impact of cobas PCR Media freezing on SARS-CoV-2 Genomic Sequencing Accuracy

\begin{tabular}{|c|c|c|c|c|c|c|c|c|c|c|c|c|c|c|c|}
\hline & PRE & & & & & POST & & & & & DELTA & PRE - POS & & & \\
\hline & Q-Score & $\begin{array}{c}\text { Accurac } \\
\mathrm{y}\end{array}$ & Non-calls & $\begin{array}{c}\mathrm{SN} \\
\mathrm{P}\end{array}$ & $\begin{array}{l}\text { Alternat } \\
\text { e allele }\end{array}$ & Q-Score & Accuracy & Non-calls & $\begin{array}{c}\mathrm{SN} \\
\mathrm{P}\end{array}$ & $\begin{array}{l}\text { Alternat } \\
\text { e allele }\end{array}$ & Q-Score & Accuracy & Non-calls & SNP & $\begin{array}{l}\text { Alternat } \\
\text { e allele }\end{array}$ \\
\hline & & $\%$ & $\mathrm{n}$ & $\mathrm{n}$ & $\%$ & $\mathrm{~N} / \mathrm{A}$ & $\%$ & $\mathrm{n}$ & $\mathrm{n}$ & $\%$ & & $\Delta \%$ & $\Delta \mathrm{n}$ & $\Delta \mathrm{n}$ & $\Delta \%$ \\
\hline 1 & 12.9 & 99.2 & 27306 & 0 & N/A & 13.0 & 99.3 & 21402 & 3 & 89.1 & -0.1 & 0.0 & 5904 & -3 & $\mathrm{~N} \backslash \mathrm{A}$ \\
\hline 2 & 13.1 & 99.3 & 4379 & 9 & 72.2 & 12.8 & 99.1 & 2570 & 6 & 86.1 & 0.3 & 0.2 & 1809 & 3 & -13.9 \\
\hline 3 & 13.3 & 99.4 & 664 & 18 & 84.7 & 12.9 & 99.2 & 1011 & 18 & 84.4 & 0.4 & 0.2 & -347 & 0 & 0.3 \\
\hline 4 & 13.7 & 99.6 & 251 & 15 & 84.1 & 13.7 & 99.6 & 12 & 15 & 87.1 & 0.0 & 0.0 & 239 & 0 & -2.9 \\
\hline 5 & 13.7 & 99.6 & 3 & 16 & 89.8 & 13.6 & 99.5 & 1 & 16 & 89.2 & 0.1 & 0.0 & 2 & 0 & 0.7 \\
\hline 6 & 13.6 & 99.5 & 0 & 11 & 88.0 & 13.4 & 99.5 & 0 & 11 & 87.8 & 0.2 & 0.1 & 0 & 0 & 0.2 \\
\hline 7 & 13.6 & 99.6 & 0 & 16 & 89.4 & 13.6 & 99.5 & 0 & 16 & 88.8 & 0.0 & 0.0 & 0 & 0 & 0.5 \\
\hline 8 & 13.6 & 99.5 & 0 & 21 & 88.9 & 13.6 & 99.5 & 0 & 21 & 88.2 & 0.0 & 0.0 & 0 & 0 & 0.8 \\
\hline 10 & 13.6 & 99.5 & 0 & 14 & 89.3 & 13.5 & 99.5 & 0 & 14 & 90.2 & 0.1 & 0.0 & 0 & 0 & -0.9 \\
\hline $\begin{array}{c}\text { Mean } \\
p-\end{array}$ & 13.5 & 99.5 & & 14 & 86.2 & 13.4 & 99.4 & & 14 & 88.0 & 0.1 & 0.0 & 761 & 0 & -1.7 \\
\hline value & & & & & & & & & & & 0.07 & 0.10 & 0.24 & 1.00 & 0.31 \\
\hline
\end{tabular}

302 Table 3 - Differences in SARS-CoV-2 sequencing accuracy and single nucleotide polymorphisms identification after 7-day freezing in

303 cobas PCR Media. Samples are presented in decreasing order of Ct value on pre-freezing ORF1 a/b RT-PCR. 